\title{
Bringing the Body into Environmental Behavior: The Corporeal Element of Social Practice and Behavioral Change
}

\author{
Chelsea Schelly' \\ Department of Social Sciences, Michigan Technological University, \\ MI, United States
}

\section{Abstract}

This paper argues that understanding environmentally responsible behavior as a constellation of practices, specifically practices that involve bodily engagement, provides the most promising avenue for future research seeking to explain and encourage patterns of behavior that are environmentally responsible and promote environmental sustainability. Drawing on scholarship on theories of practice, and sociological research on alternative technology adoption and alternative communities, this essay brings attention to the corporeal nature of practice. To understand environmentally responsible behavior, scholarship must acknowledge that humans are reflexively engaged with the material world, and engaging in alternative practices means engaging in alternative bodily habits, routines, and rituals. Empirical research that focuses on the corporeal elements of environmental practice may offer fruitful insight for enhanced scholarship in environmental social science and the promotion of environmental engagement.

Keywords: alternative technology adoption, corporeal sociology, environmentally responsible behavior, practice theory, social practice

\section{Introduction}

A wide range of scholarship aims to understand the relationship between human societies and environmental resources (Catton \& Dunlap, 1978; Dunlap \& Catton, 1979). One line of work in environmental social sciences focuses on understanding human behavior and seeks to explain why some humans act in ways that are considered environmentally responsible by engaging in what is often referred to as sustainable consumption. Classic research on environmentally responsible behavior borrowed from social psychological frameworks, such as the norm activation model (Schwartz, 1973, 1977). Another classic framework is the theory of planned

1 Corresponding author: cschelly@mtu.edu. 
behavior (Ajzen, 1985, 1991; Ajzen \& Fishbein, 1977, 1980). These classical foundations, particularly the theory of planned behavior, still guide the selection of variables included in models used to explain environmentally responsible choices like recycling, energy conservation, and renewable energy technology adoption (see Heberlein, 2012).

More recent scholarship uses the language of sustainable consumption to explore why some humans choose environmentally responsible choices. There are multiple perspectives used to grapple with issues related to sustainable consumption (Shwom \& Lorenzen, 2012). This field continues to be conceptually open ended, with no clear consensus on what drives humans to engage in practices that are considered beneficial for, or at least less damaging to, the natural world.

One trend in this wide body of scholarship is what has elsewhere been called a "variables paradigm" (Abbott, 1997). Thinking in terms of variables that can be tested through a statistical model, scholars have searched for clues that some measure of environmental concern, environmental attitudes, and environmental values may explain individual intention to engage in environmentally responsible practices. Yet, this research continues to produce weak predictions at best (Bamberg \& Möser, 2007; Heberlein, 2012; Steg \& Vlek, 2009).

Nevertheless, this research paradigm arguably continues to dominate explorations into sustainable consumption practices (see, for example, Clayton et al., 2015; Clements et al,. 2015). Some survey-based research does attempt to capture actual environmental behaviors (understood more accurately as reported behaviors), and to examine their relationship to other behaviors, like political behaviors (Willis \& Schor, 2012). This research, importantly, moves beyond a citizen-consumer dichotomy (Meyer, 2015).

The understanding of environmental behaviors outlined below offers a conceptual foundation and framework for increasing the meaning and relevance of work in environmental social sciences. This foundation is useful in research that explores how humans engage in behaviors that change their impact on their natural world by reshaping behavioral practice to be less resource intensive, more resource efficient, and overall, more environmentally responsible and sustainable. The conceptualization of environmentally consequential human behaviors and how humans may adopt less environmental damaging patterns of behavior is important for driving research agendas and research design; the conceptual tools scholars use to understand environmentally impactful human behaviors shape the way we see human action and the lenses through which we view the possibilities of behavior.

Arguably, the concepts used to guide scholarship in environmental social sciences also influence how environmental policy is discussed, formulated, and evaluated. This paper proposes that scholarship in theories of practice are a significant and 
important alternative conceptualization for understanding how human behavior that affects the environment can be conceptually understood and empirical examined. Further, theories of social practice can be increasingly refined by drawing explicit attention to the corporeal elements of human engagement with the environment; this attentiveness to the bodily elements of environmental practice can also inform improved policy.

Theories of practice are based on a strong foundation of sociological theory (Bourdieu, 1977; Giddens, 1984), have a clear theoretical articulation (Reckwitz, 2002; Schatzki, 1996), and are increasingly being used to explain sustainable consumption patterns (see Cohen et al., 2013; Warde, 2015; Welch \& Warde, 2015). This paper argues, specifically, that theories of practice can help scholars understand human behavior precisely because they focus analytical attention on the practical, bodily, corporeal engagement involved in the daily human activities that have such consequential environmental impacts. An explicit focus on corporeality built on the foundation of theories of practice, I argue, can shed new light on understanding patterns of human practice and can help us, as scholars, more accurately understand and help to explain both the barriers to and motivations for environmentally responsible human practices. Conceptualizing environmentally significant human behavior as corporeal patterns of practice can also help improve environmental policy.

\section{Practice theory and corporeality}

Theories of practice are based on the conceptual foundations offered by the work of Pierre Bourdieu, Anthony Giddens, and Michel Foucault, specifically as these thinkers describe human action as largely habitualized, routinized, and unthinking practices (see Reckwitz, 2002; Schatzki, 1996). Social life involves the unfolding of everyday, moment-by-moment rituals (Collins, 2004), and theories of practice emphasize focusing on practice as the unit of analysis in sociological research. A social practice can be defined as "a routinized type of behaviour which consists of several elements, interconnected to one another: forms of bodily activities, forms of mental activities, 'things' and their use, a background knowledge in the form of understanding, know-how, states of emotion and motivational knowledge" (Reckwitz, 2002, pp. 249-50).

Thus, practices involve bodily, emotionally, and cognitively intertwined processes of engagement. Practices can be understood as the combination of a behavior and a norm; in our daily doings, human beings are enacting the kinds of behavior they consider normal, acceptable, and ideal in everyday life. Importantly, practices are social, in that groups of people who may differ in other ways also may engage in similar sets of everyday practice. Practices are also habitual; they are often and largely unthinking patterns of engagement, routines that do not necessarily enter 
the level of conscious thought for individuals. Finally, practices necessarily involve engagement with the material world (Schatzki, 2010); social practices define how humans engage with the material systems around them, including the natural world and the multitude of technologies and infrastructures that affect the environment.

Theories of social practice can help explain the stability of human practices that affect the natural world; humans continue to use energy in particular ways for particular tasks (Shove \& Walker, 2014), despite the increasing acknowledgment and understanding of the environmental impacts of using energy primarily generated from fossil fuels. An emphasis on social practice can also help explain how and why constellations of behavior can change. One line of work in this vein emphasizes how systems of provision shape and constrain human behaviors (Spaargaren, 2003); human constructions, from bus schedules to energy policies, work to shape human behavior, often in unforeseen and unexplored ways. Another line of inquiry focuses on how behavioral norms emerge, develop, and then become invisible (Shove, 2004). Patterns and routines regarding, for example, bathing human bodies and laundering clothes have changed over time, but patterns of social practices are nonetheless largely consistent within social groups and involve normalized conventions that shape both individual behaviors and expectations of the behaviors of others.

Theories of social practice highlight the importance of understanding the materiality of environmentally responsible behaviors. Changes in practice that lessen the environmental damages caused by human activity involve changes in how individuals and groups of individuals interact with material things and the material systems that support everyday life (Schatzki 2010). Theories of social practice also implicitly suggest the importance of focusing on bodily engagement, the ways in which human corporeality is implicated in the environmental impacts of everyday life. Focusing on the bodily element of behavioral change is consistent with the intellectual lineage of theories of practice, such as Bourdieu and the notion of habitus $(1977,1984)$. Debbie Kasper (2009) uses the concept of eco-habitus to draw attention to the bodily element of engagement with the material and social world. Sarah Pink (2012, 2015) argues for utilizing ethnographic methods that tap into the role of sensory experiences in the social world. However, scholarship drawing on theories of social practice is rarely explicit in acknowledging that changes in environmental behavior are fundamentally corporeal changes, requiring humans to do something different with their bodies. Some understandings of social practices theories seem to ignore the corporeal element of environmentally significant patterns of human behavior. Defining social practices in terms of "material, meaning, and competence" (Shove \& Pantzar, 2005) implicitly references bodily knowledge, as experiential and corporeal knowledge is necessary for competence.

However, this perspective largely removes the very physical, bodily, and emotional elements of practices and does little to explicitly bring corporeality to the center of the analysis. I argue that the physical, material, and corporeal elements of bodily practice 
are essential, and in many case temporally prior, to either stabilization or change in meanings. In other words, what humans do with their bodies can change how they think about the meanings of their actions, and this prioritization of corporeal experience is key for understanding environmental behaviors. Thus, social practice perspectives are arguably strongest in their conceptual and explanatory power when they explicitly highlight the bodily elements of social engagement. Further, a theory of social practices that pays explicit attention to corporeality provides an innovative tool for understanding and seeking to change environmentally significant human behaviors.

Adopting a social practice perspective involves the possibility of recognizing the corporeal nature of environmental practices as a fruitful domain of study. In short, living with different environmental practices and environmentally responsible technologies means doing different things with your body, and new bodily competencies can become the foundation for new patterns of understanding and meaning; focusing on corporeal patterns of engagement may offer new insight for advancing scholarship aiming to understand, and potentially change, environmentally impactful human behaviors.

Corporeal sociology can be defined as "an approach towards the structuring of human relationships and identities centred around the socially shaped embodied subject" (Crossley, 2001; Shilling, 2004, p. 473). Corporeality also has a long intellectual tradition in sociological research (Shilling, 2001, 2007). Bourdieu (1977, 1980) was not the first to focus on the bodily patterning of social life. Marcel Mauss (1973 [1934]) wrote about the techniques of the body, learned patterns of behavior and tool use that could only be explained sociologically. He also wrote about how patterns of physical organization corresponded to rhythms of bodily behaviors in social groups that could change across space and time (1979). Later scholarship highlights the corporeal element of socially organized behaviors, both in the solidarity created by rituals of bodily interaction (Collins, 2004) and in the social conflict created by differentiation through physicality (Shilling, 2004). Following the tradition of pragmatism, a focus on corporeality in social theory can also highlight the potential for creative action, when individuals engage in new and different bodily behaviors as a form of social behavior and identity, representing new possibilities for situated action (Joas, 1996).

Bringing together theories of practice and corporeal sociology focuses attention on the ways human behaviors involve patterned bodily interaction with material systems; this interaction is important because it inevitably affects the natural world through varying patterns and kinds of resource use and environmental degradations. Theories of practice suggest that social behaviors represent not only material impacts, but also codified norms and expectations of behavior, so that when we as scholars study a behavior, we are studying physical action and a socially accepted expectation of behavior. Theories of practice can be further strengthened with 
a focus on corporeality, highlighting that changes in behavior really are changes in bodily engagement, which can themselves initiate changes in social meanings. This conceptualization offers fruitful insight for understanding behaviors that minimize the negative impacts of human activities on the natural world.

\section{Examples of the corporeality of alternative environmental practice}

Some examples from research on alternative technology adoption and alternative environmental practice illustrate the value of examining environmental practice with an emphasis on corporeality. These examples demonstrate that a focus on bodily practice, specifically changes in bodily practice that occur through technological and behavioral changes, highlights important empirical realities that may be missed through scholarly orientations emphasizing the values, beliefs, demographics, or politics associated with environmental behaviors. Drawn from research with solar energy technology adopters (Schelly, 2014b, 2014c) and individuals living in alternative and intentional communities (Schelly, 2014a, 2017), these examples are not meant to be comprehensive but rather merely illustrative. The aim is to demonstrate the possibilities for improved understanding of environmentally responsible behaviors and sustainable consumption choices via a focus on how transformed social practices also entail transformations in bodily, corporeal experience.

These data were collected via qualitative interviews and ethnographic participant observation among a wide array of alternative technology adopters and members of communities that demonstrate alternative possibilities for sustainable residential living. Data from solar technology adopters were drawn from interviews with 96 residential homeowners who have adopted solar electric technology in two United States (US) states (Schelly, 2014b, 2014c). Data from alternative and intentional communities were drawn from four case studies (Schelly, 2017) of communities in the US wherein people are living with alternative systems for electricity, water, waste, and transportation, among other things, representing experiments in alternative living that have existed for decades. The author spent time in each community engaged in ethnographic fieldwork and participant observation, interviewing residents both formally and informally and living within the communities as an identified researcher.

In addition to asking about motivations and experiences, participants were explicitly asked about behavioral patterns, or practices, and specifically about changes in practice since adopting the new technology or lifestyle choices. Both development and analysis of questions focused on discussions of practice, in terms of materials and meanings, and physical, bodily engagement. Their responses demonstrate that 
asking people to describe their practices and changes in practice can provide rich insight into the corporeal elements of environmentally impactful technology use in residential life. Further, it demonstrates the dominance of issues related to physical engagement in environmental behaviors and changed bodily behaviors as central to the changes experienced when living with alternative technologies and/or in more sustainable lifestyles.

The first example comes from studying homeowners who have installed residential solar energy systems. When a residential household chooses to install a solar electric system, also known as photovoltaic (PV), to produce electricity, they have the choice of connecting to the wider electric utility grid or using a battery storage system to keep their electricity generation "off the grid." Battery storage systems are expensive, require maintenance and replacement, and the materials involve significant environmental impacts and exposure hazards. Further, many utilities offer to purchase any electricity produced in excess of household consumption through what is called a net metering agreement. The vast majority of homeowners who are already connected to the electricity utility grid choose to install "grid tied" solar systems when adopting PV technology.

Given that the customer-installer is still connected to the larger utility network, there is no real imperative to conserve electricity usage after installing a PV system, because the customer is never going to run out of power, as is possible with an off-grid system. However, homeowners who have installed PV at home commonly discuss ways that their behavior changed after adopting solar electric technology; these behavior changes highlight the corporeal nature of social practice. Homeowners almost universally talked about being more aware of their electricity consumption after installing their PV systems, and thus, changing energy behaviors like turning lights off, putting appliances on power strips to avoid phantom loads, and replacing old appliances with new, high-efficiency models. Many homeowners talked about walking outside to see their electric meter on their home spin backwards on sunny days (indicating that electricity production is exceeding consumption), and about how getting outside multiple times a day to watch an electricity meter was a very new and totally unexpected behavior. One homeowner even talked about changing the landscape alongside his home because he had destroyed the grass by walking to see his meter so often. These changes in lived experience in residential life were accompanied by changed emotional experiences, such as excitement or disappointment about weather in relation to how it affected electricity production and a described sense of anxious joy in checking one's production and consumption via meter checks or online tracking systems.

Some homeowners, when installing a residential PV system, have the option and choose to invest in electronic monitoring software that allows them to view and track their home's energy production and consumption through an online platform. Homeowners who had this capability reported ways their behavior 
changed even further in response to this ability to see their home's energy system at work. Some homeowners talked about having the website open all day at work and becoming so tuned in to the energy readings that they could tell how cloudy or sunny it was at home, or whether someone was using the microwave or clothes washer. For these homeowners, seeing how electricity usage peaked when certain appliances were in use drove further behavior changes in either replacing appliances or modifying usage of them. These homeowners experienced changes in the materials, meanings, and competencies involved in everyday life, elements drawn out by past work based on theories of social practices. However, these homeowners also described experiencing changes to their bodily and emotional routines as they came to associate the experience of opening a web browser with affective responses to signs regarding the weather or usage at home. In these examples, the key point is that these solar technology adopters changed their bodily routines and behaviors, their corporeal patterns shifted, after installing their residential PV systems. These changes to bodily experience corresponded to changes in their emotional lives. These changes were not materially required by the adoption of the system. However, they do suggest that alternative technology adoption involves important changes in bodily practice.

Further examples come from ethnographic research experiences in three specific intentional communities across the US and one alternative residential community. These communities range in population from 50 adults and their children to approximately 200 members, and vary widely in how they organize their economies, living situations, and the use of other material systems like transportation, food, energy, and water. However, all four communities demonstrate how changes in social practice in response to adopting alternative material systems involve changing the daily corporeal experience of residential dwellers.

In all of these communities, the private automobile and the bodily experience of driving a car are much less central than they are for most Americans; two of the four communities do not allow personal vehicles or vehicle travel within the community at all (with exceptions made for practical reasons involving construction, maintenance, and deliveries); electric golf carts, many charged with solar power, are a common way to commute among neighbors' homes in the third; and the fourth community comprises off-grid homes; thus, homeowners do not need to commute for work nearly as much, some choosing to work very little or not at all, because they do not have monthly bills associated with electricity, water, or waste. In all four communities, people also use cars for commuting to work far less often than most Americans do; one of these communities is a labor-sharing community where everyone works for the community within the community's boundaries, while two others work to develop and maintain internal economies and work opportunities without the mandate of labor or income sharing. This means that the bodily habit of driving a personal vehicle is corporeally altered in these communities, and people 
living in these communities recognize that they, to varying degrees, let go of a constellation of learned bodily behaviors by choosing to drive less. To relate, think of the last time you avoided driving for a week, or a month, or a year, and how unfamiliar it may have felt the next time you got behind the wheel. By changing patterns of driving practice, they change their corporeal experience, and minimize the environmental impacts associated with that practice.

In one of these communities, the lack of access to a personal automobile is described as a luxury rather than a sacrifice, because as one member put it, "there's someone to do the shopping for you." People can avoid driving personal automobiles; thus, they have more time to engage in other kinds of activities they enjoy more. In another community, members are described as "car less" rather than "carless" because members all drive less often but all do have access to vehicles if they choose, again changing the way people use their bodies, spend their time, and think about personal freedom (as the freedom to avoid driving rather than the personal freedom associated with a personal vehicle).

These communities involve myriad other forms of alternative environmental practice, with associated changes in corporeality. All four communities engage in food production, at varying scales and levels, but with more regularity than most Americans. In one of these residential communities, food is grown inside the house via internal plant beds that also serve as a water filtration system. Growing vegetables, keeping poultry and livestock, and maintaining perennial fruit and nut bearing plants all involve bodily engagement with the natural world that is simply not part of daily practice for the majority of Americans. Two of these communities are organized, in varying degrees, around the regular production of community-scale meals, so that the preparation and consumption of food also involves a different corporeal experience, as people are always in the company of other community members for meals. This changes not only the bodily experience of eating, but also the meaning of meals. In one of these communities, members live in shared living group housing, so they do not have the corporeal experiences associated with a single family home.

All four communities also use, to varying degrees, some combination of alternative technological systems, including solar electricity and solar hot water, rainwater collection and wastewater treatment, and composting of human organic waste. These all involve changes in routinized, bodily practice and the associated corporeal relearning of habits and norms related to energy and water awareness, physical engagement with system maintenance, and the time spent in various bodily activities. Perhaps the use of composting toilets is most interesting for illustrating the argument here. In one of these communities, each residential structure has flush toilets but there are also outhouses with composting toilet systems throughout the community. During my time in the community, I was told by members and observed firsthand that many members of the community use these outhouses exclusively, never 
flushing a toilet full of potable water to discard their waste. Although it was not materially required of them, these members chose to change a very bodily activity, demonstrating how alternative material systems are associated with new corporeality. In another community, composting human waste is a community commitment. In this community, the use of an alternative material system is associated with a new set of bodily activities (including both men and women urinating outside, and the need to physically haul human waste to a centralized composting facility) and a new set of social practices that incorporate new social norms (a diminished social taboo around human waste, and the raising of children who think waterless composting of human waste is normal while flush toilets are unusual and strange).

The purpose of these examples is to highlight the conceptual argument. Environmentally responsible behaviors often require changes in engagement with the material world. Further, theories of social practice can help scholars explore and understand both the maintenance of practices and the ways that changed practices involve constellations of material, bodily, and normative elements. However, theories of social practice can be further developed through an explicit focus on corporeality, recognizing that environmentally responsible behaviors involve new forms of bodily engagement with the material and physical world and corresponding emotional experiences that result from new technological arrangements and bodily practices. Interrogating the role and significance of an alternative corporeality becomes, then, a central task for scholars interested in understanding environmental behaviors. Further, the prioritization of corporeal experience as central to changing environmental behaviors suggests that opportunities to engage in new bodily habits and competencies through experiential learning, small-scale gardening, or courses or fieldtrips associated with environmentally responsible behaviors, have the potential to shift meanings through the very process of shifting bodily practice.

\section{Implications for empirical work}

Studying social life is fundamentally about studying social relationships (Emirbayer, 1997), and studying human-environment interactions can also relationally defined as "the application of our sociological imaginations to the connections among people, institutions, technologies and ecosystems that make society possible" (Lockie, 2015, p. 140), then the strength of theories of social practices is in their attention to the relationship between structures (material, physical, or institutional systems), norms, and behaviors. Theories of social practices highlight how routine behaviors with significant environmental consequences become stabilized and inscribed in the built environment, the policy world, and the mental categorizations of individuals within a social world. This paper argues that theories of practice can offer deeper 
insight when combined with an explicit focus on the corporeality of environmental behavior and attentiveness to how environmentally responsible behavior involves altered corporeal experiences.

One implication of this move for empirical research on environmentally responsible behavior and/or sustainable consumption is a rethinking of agency and choice (Emirbayer \& Mische, 1998; see Røpke, 2009). It is possible for corporeal subjectivities to be altered through changes of practice without conscious intention or reflection on that change. In other words, research projects that ask participants about their motivations or intentions might not be as revealing (for both researchers and participants) as studies that ask about people's actions. For residential PV adopters, changing their everyday practices so that they could physically monitor their energy usage through either a meter or a website was not a conscious choice to change their corporeal experience to be more engaged with energy usage; the altered bodily practices were a largely unreflective response to being able to see energy usage in new ways. From a perspective guided by theories of social practices, intention is less significant than action; from a framework that also emphasizes corporeality, it is the physicality of that action and the unthinking ways environmental behaviors may create new patterns of bodily engagement that deserves empirical attention.

This focus may suggest a need for research based on qualitative studies, which can dig deep to focus on understanding constellations of social practices as bodily, corporeal experiences (Schelly, 2016a). However, survey research can also be used to ask about bodily engagement with environmental practice. Instead of focusing on demographic or attitudinal variables alone, research into environmental motivations and behaviors may benefit from attention to ways of capturing bodily process and corporeal experiences that may not be entirely conscious or the rational consequence of calculated consideration. This kind of research may benefit from an explicit focus on the importance of, and the need to accurately measure, corporeal experiences and patterns in the bodily elements of social practices.

Another implication for empirical work is the need, as highlighted above, to provide opportunities for new bodily experiences and to further examine how changed bodily practice can, and sometimes does, lead to new understandings and meanings. Maintaining environmentally responsible behaviors is often a challenge for those seeking to study and create behavioral change, but understanding the role of changing physical bodily experiences as an initial step in the process to change meanings and acceptance of new materialities may allow us to further understand the opportunities for sustained change that starts with changed corporeal experience. 


\section{Implications for environmental policy}

Scholars working in the intellectual domain of theories of social practices have already pointed out how other conceptualizations of human behavior dominate policy-making to the detriment of actual policy impact (Schelly, 2016b; Kennedy et al., 2016; Shove, 2010). By focusing on a contextualization of behavior that prioritizes the individual, environmental policies may attempt to educate the public or shift individual values to encourage environmentally responsible behaviors; these policy frameworks render invisible the social contexts in which practices are shaped and solidified. Theories of social practices can help improve both policy creation and policy evaluation by considering how policies shape both the possibilities and the limitations for individuals to change shared everyday routines in ways that mitigate environmental harms.

This perspective can draw explicit attention to how the specifics of policy design and implementation work to shape what people do with their physical bodies as they engage with the material world through everyday practice (Schelly, 2014d). Some environmental policies may have unintended consequences when it comes to shifting actual physical behaviors. Thus, policy analysis must consider corporeal outcomes when seeking to understand policy effectiveness.

Further, while scholars examine the impact of particular environmental policies on bodily practice, policy-makers may begin by seeking to further understand how people use their bodies to engage in everyday routines that affect the environment, and how including the body in environmental policy-making may improve policy impact. Policy frameworks that begin with the body, recognizing the corporeal aspects of everyday life and how environmental harms are created by the bodily ways that people go about interacting with the world, may offer fresh insight into creating change through environmental policy.

One specific example of this to come out of the research described above involves the idea that, given the expense of renewable energy technologies, individuals and communities should prioritize opportunities to increase energy efficiency before investing in renewable energy systems. As described above, research with residential PV adopters suggests that energy efficiency becomes more corporeally engaging only after installing a renewable energy system. This demonstrates how bodily engagement with new social practices may itself create opportunities for further changes in practices that are associated with environmental responsibility, challenging the arguably dominant discourse in energy transition policy frameworks regarding the temporal ordering of efficiency before renewable energy technologies.

Thus, attentiveness to social practices as corporeally significant, bringing the body into research on environmental behaviors, can help inform, improve, and evaluate future policies meant to address environmentally significant patterns of human 
engagement. From very localized policies regarding the use of clotheslines or front yard gardens to national policies regarding support for renewable energy technology, a corporeal approach suggests that policies can be conceptualized and evaluated not only in terms of efficiency or trade-offs measured by empirical metrics, but also in terms of the extent to which they allow, encourage, or facilitate changes in the embodied experiences through which humans relate to the natural world. As corporeal beings, humans engage in social practices imbued with physical, bodily, and emotional elements. It is arguably only by attentiveness to these elements that we can seek to change environmental policies to best address how patterns of bodily human engagement contribute to the environmental harms caused by the practices of everyday life.

\section{Conclusion}

This paper is not meant to suggest that theories of social practices ought to be the perspective adopted by scholars across the environmental social sciences. Environmental social sciences have offered many significant conceptual ideas; many of the classical theoretical foundations of the field are still useful today. Ecological modernization theory (Spaargaren \& Mol, 1992), for example, has generated vigorous dialogue and debate, and is still utilized in contemporary empirical work (Scanu, 2015). The concepts of the treadmill of production (Schnaiberg, 1980; Schnaiberg \& Gould, 1994) and the treadmill of accumulation (Foster, 2005) also continue to offer fresh insight for empirical research (Griffin et al., 2015). Recent scholarship continues to contribute to the conceptual development and intellectual growth of the field (Gunderson, 2015, 2016).

Rather, focused specifically on the domain of environmentally responsible behavior and sustainable consumption, theories of social practices offer one important line of thinking to contribute new and valuable insight for understanding human behavior. Further, this paper suggests that theories of social practices are most conceptually useful and empirically explanatory when explicitly attentive to the corporeal elements of social practices. This paper argues that theories of practice are aptly suited for such a domain of study precisely because they have the potential to focus our attention on what may matter most for changing environmental behaviors: understanding the socially organized ways that groups of individuals corporeally interact with the material world in ways that have significant environmental consequences.

There are patterns of physical, bodily engagement with the material world, and the dominant patterns of social practices contribute significantly to the degradation of the natural world. From the ways human beings use energy in the processes of flipping light switches, flushing toilets, and innumerable other habitual tasks, to the patterns of practices in our shopping and driving and disposal of waste, 
human beings are-through their corporeal subjectivities—causing harm to the natural environment. Understanding the bodily dimension of social practices offers an important opportunity for scholars and policy-makers interested in examining forms of behavior that minimize the environmental harm caused by the enactment of social practices in everyday life.

Emphasizing the corporeal elements of social practice as a key element in creating sustained environmentally responsible behaviors, by recognizing that changed bodily experiences can themselves reshape understandings and meanings, also suggests the importance of providing opportunities for alternative corporealities to create change. Whether it be by allowing clotheslines or front yard gardens or providing experiential learning opportunities associated with changes in use of energy, water, transportation, food, and waste, new corporeal experiences can create new social meanings and contribute to sustained behavioral change (Schelly, 2017). This perspective suggests that all environmentally responsible behaviors and forms of sustainable consumption, from recycling to renewable technology adoption, share a common element of corporeality; they all involve changing bodily behaviors in ways that may consequently change subjectivities and shifting shared possibilities for future change.

\section{References}

Abbott, A. (1997). Of time and space: The contemporary relevance of the Chicago school. Social Forces, 75, 1149-1182. doi.org/10.1093/sf/75.4.1149

Ajzen, I. (1985). From intentions to actions: A theory of planned behavior. In J. Kuhl and J. Beckman (Eds.), Action-control: From cognition to behavior (pp. 11-39). New York: Springer. doi.org/10.1007/978-3-642-69746-3_2

Ajzen, I. (1991). The theory of planned behavior. Organizational Behavior and Human Decision Processes, 50, 179-211. doi.org/10.1016/0749-5978(91)90020-T

Ajzen, I., \& Fishbein, M. (1977). Attitude-behavior relations: A theoretical analysis and review of empirical research. Psychological Bulletin, 84, 888-918. doi.org/10.1037/00332909.84.5.888

Ajzen, I., \& Fishbein, M. (1980). Understanding attitudes and predicting social behavior. Englewood Cliffs, NJ: Prentice-Hall.

Bamberg, S., \& Möser, G. (2007). Twenty years after hines, hungerford, and tomera: A new meta-analysis of psycho-social determinants of pro-environmental behavior. Journal of Environmental Psychology, 27, 14-25. doi.org/10.1016/j.jenvp.2006.12.002

Bourdieu, P. (1977). Outline of a theory of practice. Cambridge, MA: Cambridge University Press. doi.org/10.1017/CBO9780511812507 
Bourdieu, P. (1980). The logic of practice. Cambridge, MA: Polity.

Bourdieu, P. (1984). Distinction: A social critique of the judgment of taste. London: Routledge.

Catton, W. R. Jr., \& Dunlap, R. E. (1978). Environmental sociology: A new paradigm. The American Sociologist, 13, 41-49.

Clayton, S., Devine-Wright, P., Stern, P. C., Whitmarsh, L., Carrico, A., Steg, L., Swin, J., \& Bonnes, M. (2015). Psychological research and global climate change. Nature Climate Change, 5, 640-646. doi.org/10.1038/nclimate2622

Clements, J. M., McCright, A. M., Dietz, T., \& Marquart-Pyatt, S. T. (2015). A behavioural measure of environmental decision-making for social surveys. Environmental Sociology, 1, 27-37. doi.org/10.1080/23251042.2015.1020466

Cohen, M. J., Brown, H. S., \& Vergragt, P. (Eds.). (2013). Innovations in sustainable consumption: New economics, socio-technical transitions and social practices. Cheltenham UK: Edward Elgar Publishing. doi.org/10.4337/9781781001349

Collins, R. (2004). Interaction ritual chains. Princeton: Princeton University Press. doi.org/ $10.1515 / 9781400851744$

Crossley, N. (2001). The social body. London: Sage.

Dunlap, R. E., \& Catton, W. R. Jr. (1979). Environmental sociology. Annual Review of Sociology, 5, 243-273. doi.org/10.1146/annurev.so.05.080179.001331

Emirbayer, M. (1997). Manifesto for a relational sociology. American Journal of Sociology, 103, 281-317. doi.org/10.1086/231209

Emirbayer, M., \& Mische, A. (1998). What is agency? American Journal of Sociology, 103, 962-1023. doi.org/10.1086/231294

Foster, J. B. (2005). The treadmill of accumulation: Schnaiberg's Environment and Marxian political economy. Organization and Environment, 18, 7-18. doi.org/10.1177/ 1086026604270442

Giddens, A. (1984). The constitution of society. Berkeley: University of California Press.

Griffin, L. N., Pavela, G., \& and Arroyo, J. (2015). Tourism and the treadmill of production: A cross-national analysis. Environmental Sociology, 1, 127-138. doi.org/10.1080/23251 042.2015 .1022930

Gunderson, R. (2015). Environmental sociology and the Frankfurt School 1: Reason and capital. Environmental Sociology, 1, 224-235. doi.org/10.1080/23251042.2015.1054022

Gunderson, R. (2016). Environmental sociology and the Frankfurt School 2: Ideology, techno-science, reconciliation. Environmental Sociology, 2, 64-76. doi.org/10.1080/23 251042.2015.1052217 
Heberlein, T. A. (2012). Navigating environmental attitudes. New York: Oxford University Press. doi.org/10.1093/acprof:oso/9780199773329.001.0001

Joas, H. (1996). The creativity of action. Chicago: University of Chicago Press.

Kasper, D. V. S. (2009). Ecological habitus: Toward a better understanding of socioecological relations. Organization and Environment, 22, 311-326. doi.org/10.1177/ 1086026609343098

Kennedy, E. H., Cohen, M. J., \& Krogman, K. (Eds.). (2016). Putting sustainability into practice: Advances and applications of social practice theories. Cheltanham, UK: Edward Elgar.

Lockie, S. (2015). What is environmental sociology? Environmental Sociology, 1, 139-142. doi.org/10.1080/23251042.2015.1066084

Mauss, M. (1973 [1934]). Techniques of the body. Economy \& Society, 2, 70-88. doi.org/ $10.1080 / 03085147300000003$

Mauss, M. (1979). Seasonal variations of the eskimo: A study in social morphology. London: Routledge \& Kegan Paul.

Meyer, J. M. (2015). Engaging the everyday: Environmental social criticism and the resonance dilemma. Cambrige, MA: MIT Press. doi.org/10.7551/mitpress/ 9780262028905.001 .0001

Pink, S. (2012). Situating everyday life: Practices and places. Sage Publications. doi.org/ $10.4135 / 9781446250679$

Pink, S. (2015). Doing sensory ethnography. Sage Publications.

Reckwitz, A. (2002). Toward a theory of social practices: A development in culturalist theorizing. European Journal of Social Theory, 5, 243-263. doi.org/10.1177/ 13684310222225432

Røpke, I. (2009). Theories of practice-New inspiration for ecological economic studies of consumption. Ecological Economics, 68, 2490-2497. doi.org/10.1016/j.ecolecon. 2009.05.015

Scanu, E. (2015). Climate governance in the post-industrial city: The urban side of ecological modernization. Environmental Sociology, 1, 102-115. doi.org/10.1080/23251042.2015. 1008384

Schatzki, T. R. (1996). Social practices: A Wittgensteinian approach to human activity and the social. New York: Cambridge University Press. doi.org/10.1017/CBO9780511527470

Schatzki, T. R. (2010). Materiality and social life. Nature and Culture, 5, 123-149. doi.org/ $10.3167 /$ nc. 2010.050202 
Schelly, C. (2014a). Are residential dwellers marking and claiming? Applying the concepts to humans who dwell differently. Environment and Planning D: Society and Space 32(4), 672-688. doi.org/10.1068/d20312

Schelly, C. (2014b). Transitioning to renewable sources of electricity: Motivations, policy, and potential. In D. L. Kleinman, K. Cloud-Hansen \& J. Handelsman (Eds.), Controversies in science and technology, Volume 4 (pp. 62-72). New York, NY: Oxford University Press.

Schelly, C. (2014c). Residential solar electricity adoption: What motivates, and what matters? A case study of early adopters. Energy Research and Social Science 2, 183-191. doi.org/10.1016/j.erss.2014.01.001

Schelly, C. (2014d). Implementing renewable energy portfolio standards: The good, the bad, and the ugly in a two state comparison. Energy Policy 67, 543-551. doi.org/10.1016/ j.enpol.2013.11.075

Schelly, C. (2016a). Understanding energy practices: A case for qualitative research. Society \& Natural Resources 29(6), 744-749. doi.org/10.1080/08941920.2015.1089613

Schelly, C. (2016b). How policy frameworks shape environmental practice: Three cases of alternative dwelling. In E. Huddart Kennedy, M. J. Cohen, \& N. Krogman (Eds.), Putting sustainability into practice: Advances and applications of social practice theories (pp. 185-203). Cheltanham, UK: Edward Elgar.

Schelly, C. (2017). Dwelling in resistance: Living with alternative technologies in America. Rutgers University Press. doi.org/10.2307/j.ctt1q1cr69

Schnaiberg, A. (1980). The environment: From surplus to scarcity. New York: Oxford University Press.

Schnaiberg, A., \& Gould, K. A. (1994). Environment and society: The enduring conflict. New York: St. Martin's.

Schwartz, S. H. (1973). Normative explanations of helping behavior: A critique, proposal and empirical test. Journal of Experimental Social Psychology, 9, 349-364. doi.org/ 10.1016/0022-1031(73)90071-1

Schwartz, S. H. (1977). Normative influences on altruism. In L. Berkowitz (Ed.), Advances in experimental social psychology, 221-279. New York: Academic Press. doi.org/10.1016/ S0065-2601(08)60358-5

Shilling, C. (2001). Embodiment, experience, and theory: In defence of the sociological tradition. Sociological Review, 49, 327-344. doi.org/10.1111/1467-954X.00335

Shilling, C. (2004). Physical capital and situated action: A new direction for corporeal sociology. British Journal of Sociology of Education, 25, 473-487. doi.org/10.1080/ 0142569042000236961

Shilling, C. (2007). Sociology and the body: Classical traditions and new agendas. The Sociological Review, 55, 1-18. doi.org/10.1111/j.1467-954X.2007.00689.x 
Shove, E. (2004). Comfort, cleanliness, and convenience: The social organization of normality. New York, NY: Berg.

Shove, E. (2010). Beyond the ABC: Climate change policy and theories of social change. Environment and Planning A, 42, 1273-1285. doi.org/10.1068/a42282

Shove, E., \& Pantzar, M. (2005). Consumers, producers and practices. Understanding the invention and reinvention of Nordic walking. Journal of Consumer Culture, 5, 43-64. doi.org/10.1177/1469540505049846

Shove, E., \& Walker, G. (2014). What is energy for? Social practice and energy demand. Theory, Culture \& Society, 31, 41-58. doi.org/10.1177/0263276414536746

Shwom, R., \& Lorenzen, J. (2012). Changing household consumption to address climate change: Social scientific insights and challenges. WIREs: Climate Change, 3, 379-395. doi.org/10.1002/wcc. 182

Spaargaren, G. (2003). Sustainable consumption: A theoretical and environmental policy perspective. Society and Natural Resources, 16, 687-701.doi.org/10.1080/08941920309192

Spaargaren, G., \& Mol, A. P. J. (1992). Sociology, environment, and modernity: Ecological modernization as a theory of social change. Society and natural resources, 55, 323-344. doi.org/10.1080/08941929209380797

Steg, L., \& Vlek, C. (2009). Encouraging pro-environmental behavior: An integrative review and research agenda. Journal of Environmental Psychology, 29, 309-317. doi.org/ 10.1016/j.jenvp.2008.10.004

Warde, A. (2015). The sociology of consumption: Its recent development. Annual Review of Sociology, 41, 117-134. doi.org/10.1146/annurev-soc-071913-043208

Welch, D., \& Warde, A. (2015). Theories of practice and sustainable consumption. In L. Reisch and J. Thøgerson (Eds.), Handbook of research on sustainable consumption, 84-100. Cheltenham, UK: Edward Elgar. doi.org/10.4337/9781783471270.00013

Willis, M. M., \& Schor, J. B. (2012). Does changing a light bulb lead to changing the world? Political action and the conscious consumer. Annals of the American Academy of Political and Social Science, 644, 160-190. doi.org/10.1177/0002716212454831 
This text is taken from Human Ecology Review, Volume 24, Number 1, 2018, published 2018 by ANU Press, The Australian National University, Canberra, Australia.

doi.org/10.22459/HER.24.01.2018.07 